\title{
COPIM
}

\section{Library Support for OA Books Workshop: the German perspective.}

\section{Agata Morka}

Published on: Aug 06, 2020

DOI: $10.21428 / 785 a 6451.91 e f 1 b 29$

License: Creative Commons Attribution 4.0 International License (CC-BY 4.0). 
This summer, as part of the WP2, we started a series of European-based workshops, aiming at gaining a better understanding of the national-specific issues surrounding collective funding for OA books from a library perspective. The first online workshop took place on July 30 th 2020.

The event was organised jointly by three European projects. COPIM, open-access.network and OPERAS-P came together to host a workshop that brought together library and university presses representatives in Germany. Despite the Urlaub period being in full swing, we managed to gather a handsome number of participants from different institutions and regions. From Karlsruhe to Berlin: we all sat down in our respective living rooms to discuss possible futures of OA books in the German context. The workshop was divided in two parts: the first one focused on the main challenges that libraries encounter when supporting OA books-related initiatives, while the second one evolved around a discussion among a proposed model for collaborative funding for OA books. A number of recurring themes emerged from our discussion.

\section{One size doesn't fit all}

National uniqueness was raised multiple times by our German colleagues and was expressed in several contexts. It was noted that Germany's federal structure results in the multiplicity of regional policies and workflows used in the academic library systems. Institution-specific OA funds and policies further strengthen the idea of individual institutions as individual players with their individual interests in mind.

Decentralisation also determines a multiplicity of approaches towards OA and it became apparent that a one size fits all model is simply not sustainable in the German context: what would work in Saxonia might be completely incompatible with the existing infrastructures in North Rhine-Westphalia.

The existing infrastructures and networks make for a lively, yet complicated landscape of OA in Germany. A plethora of OA-related projects exists, with the open-access.network, the National Contact Point Open Access or the recent ENABLE! initiative proving that the soil is fertile for OA-monographs related discussions. In terms of the BPC-alternative collective funding models for OA books, Knowledge Unlatched is the most recognisable actor on the German market, with the majority of the workshop participants being familiar with its scheme. There is also a strong tradition of university presses in Germany, promoting open access and publishing OA books.

It was therefore suggested that any new OA book initiative, based on collaborative funding, if it is to be successful in Germany, needs to recognise these unique national circumstances. 


\section{On scarcity and abundance: the road blockers}

When asked about the main challenges in facilitating OA books-related initiatives the participants identified several features conspicuous by their scarcity in the German setting: funding, resources, OA book coverage in main discovery systems and OA-awareness among authors. It was also pointed out that workflows surrounding $O A$ books are complex and difficult to handle, especially when it comes to legal frameworks and licensing.

On the other hand, it turns out that the abundance of choices might be just as challenging as the lack thereof. Participants voiced their frustration over the multiplicity of existing OA book initiatives, often operating on different business models and offering different services. This plethora of options makes it difficult to make a sound decision as to which project to support and which to reject.

\section{Yes or no?}

How do libraries in Germany decide on supporting OA book initiatives? Among the important factors influencing these decisions the issue of transparency perhaps shone the brightest. Participants discussed both transparency in the governance structure, where a non-commercial and collaborative character of proposed initiatives ranked high and transparency in cost calculations, where a fair deal was asked for. Its fairness, rather than on low prices, was to be based on clear cost calculations, so that all stakeholders would be aware of how the money is spent and what it is exactly that they are paying for. They were also in favour of open-source software used in the development of any proposed initiatives and called for a tangible output and easily measurable benefits, which would justify the institution's engagement in any given project.

The question of OA content quality was hotly debated in the breakout room discussions. The need for "seals of approval" coming from existing actors such as Scopus or legacy publishers was frequently noted. Such an approach makes the shift towards innovative models based on open infrastructure and collaboration somewhat challenging in Germany. Participants stressed the fact that the proposed content, rather than any given business model, is what constitutes the final yes or no for libraries. "We are buying content, not a business model"- we heard one participant saying, expressing what seemed like a common need among participants: the need for control over a title-based selection of OA books.

Thank you to our co-hosts and all the participants: we have learned a great deal from you! This event was the first one of the series of European-based workshops in which we talk about issues surrounding collective funding models for OA books. Our next stop this summer is Central Europe, so stay tuned for more insights from the Polish perspective! 
*Image of the Reichstag dome by Oh-berlin.com, under CC-BY 2.0 